\title{
As percepções sobre a democracia no Brasil: os valores políticos dos deputados estaduais paulistas, paranaenses e catarinenses
}

\author{
The perceptions of democracy in Brazil: the political values of states \\ legislators paulistas, paranaenses and catarinenses
}

\begin{abstract}
Riberti de Almeida Felisbino*
Pesquisador associado ao Programa de Pós-Graduação em Ciências Sociais, Escola de Filosofia, Letras e

Ciências Humanas, Universidade Federal de São Paulo (campus Guarulhos), Guarulhos, SP, Brasil

e-mail: ribertialmeida@yahoo.com.br

*autor correspondente

\section{Maria Teresa Miceli Kerbauy}

Pesquisadora do CNPq e docente do Programa de Pós-Graduação em Sociologia, Universidade Estadual Paulista (campus Araraquara), Araraquara, SP, Brasil e-mail: kerbauy@travelnet.com.br
\end{abstract}

RESUmo Neste artigo pretendemos apresentar e analisar as percepções dos deputados estaduais pertencentes às elites parlamentares das Assembleias Legislativas dos Estados de São Paulo, Paraná e Santa Catarina sobre a democracia. As opiniões dos paulistas foram coletadas com a ajuda de um questionário auto-administrado e estruturado, enquanto dos paranaenses e catarinenses foram coletadas com as pesquisas "As elites administrativas, parlamentares e partidárias do Paraná, 19952006" e "Elites políticas e a democracia: os valores políticos dos parlamentares catarinenses da $16^{\circ}$ Legislatura, 2007'. Após o tratamento das suas percepções políticas, elas revelaram que i) a democracia está estável, ii) ela é superior a qualquer outro tipo de regime, iii) apresenta um conteúdo de apoio sociopolítico sustentado em algumas políticas sociais estatais e na utilização do voto e iv) a democracia conta com apoio das diversas opções ideológicas.

PalaVRas-Chave Valores políticos; Democracia; Assembleia Legislativa; Elite parlamentar; Deputado estadual.

ABSTRACT This paper analyzes the opinions of legislators members of parliamentaries elites of Legislative Assemblies of the States of São Paulo, Paraná and Santa Catarina on democracy. The opinions of legislators paulistas were collected using a questionnaire selfadministered and structured, while the opinions of legislators paranaenses and catarinenses were collected with the surveys "As elites administrativas, parlamentares e partidárias do Paraná, 1995-2006" and "Elites políticas e a democracia: os valores políticos dos parlamentares catarinenses da $16^{\circ}$ Legislatura, 2007". The results were: $i$ ) democracy is stable, ii) it is superior to any other type of regime, iii) is supported by some social policies and the use of voting and iv) democracy has support of various ideological currents.

KEYWORDS Political values; Democracy; Parliamentary elite; Legislative Assembly; State legislator. 


\section{Introdução}

$\mathrm{O}$ ordenamento constitucional inaugurado pela Lege Majore de 1988 instituiu um novo desenho e os estudiosos da política brasileira têm se interessado cada vez mais em compreender o funcionamento desse desenho. Com os primeiros estudos de Argelina Cheibub Figueiredo e Fernando Limongi no início dos anos 90, os estudiosos vêm acumulando conhecimentos sobre o presidencialismo brasileiro e a combinação desse sistema de governo com outras instituições Figueiredo e Limongi (1999). Essa dedicação tem criado um campo de pesquisa específico no interior da Ciência Política, conhecido como Estudos Legislativos, focado na relação dos poderes constitucionais da República e nas instâncias institucionais adjacentes a esses poderes.

Após os primeiros trabalhos de Argelina Cheibub Figueiredo e Fernando Limongi sobre a Câmara dos Deputados, muitos estudos sobre as Assembleias Legislativas foram ou estão sendo desenvolvidos. Os trabalhos de Abrúcio (1994, 1998), Abrúcio, Teixeira e Costa (2001), Abrúcio, Pó e Clemente (2008), Anastásia (2001), Andrade (1998), Braga (2006), Couto (1998), Domingues (2001), Grohmann (2001), Holanda (1990), Machado (2008), Moraes (2001), Pait (1990), Pereira (2001), Souza (2008), Tomio e Ricci (2008, 2010), Rocha e Costa (2010), Montenegro (2010) e outros representam a diversidade analítica sobre o estudo do poder Legislativo estadual no Brasil. A maioria das análises empreendidas por esses autores mostra o funcionamento das Assembleias Legislativas estaduais e as suas relações com os poderes Executivos no processo de formação das leis.

Apesar do crescimento dos estudos da casa Legislativa estadual no Brasil, a elite parlamentar desse poder permanece um grupo relativamente desconhecido no interior das Ciências Sociais. A importância dessa elite e sua atuação no processo decisório ainda não foram devidamente exploradas. Importa ressaltar que essa elite parlamentar não é composta por todos os membros do poder Legislativo. Ela é constituída por um pequeno grupo de parlamentares que apresentam algumas habilidades ou privilégios que possibilitam aos membros desse seleto grupo a tarefa de coordenar e decidir pelos demais colegas da casa Legislativa (Felisbino, 2007). Noutras palavras, a capacidade de tomar e impor decisões a todos os membros concentra-se nesse pequeno grupo muito restrito, ou seja, na elite parlamentar da casa.

Tomando em consideração o que foi exposto, neste artigo focamos nas elites parlamentares das Assembleias Legislativas dos Estados de São Paulo, Paraná e Santa Catarina e o ponto de partida que o orientou foi o baixo apoio dos brasileiros à democracia.

Nos últimos anos, o processo de consolidação da democracia latino-americana tem sido um tema que vem sendo estudado por muitos estudiosos das Ciências Sociais. Esse interesse pode ser explicado pela importância que tal regime representa na história política da América Latina, marcada por longas violências decorrentes dos governos militares. Dentre as várias pesquisas desenvolvidas, pode-se destacar o interesse pela análise das opiniões dos cidadãos sobre a funcionabilidade do regime democrático.

Ao analisar a democracia brasileira, José Álvaro Moisés ressalta que ela está aparentemente consolidada, mas as pesquisas de opinião do Latinobarómetro têm revelado que os brasileiros não confiam nas suas instituições, sobretudo na própria democracia. Para esse autor, essa desconfiança pode criar um

[...] ambiente favorável a que os membros da comunidade política se sintam descomprometidos com a vida pública, podendo recusar-se a cooperar com as diretrizes do Estado ou ignorar as leis e as normas que regulam e organizam a vida social e política. (Moisés, 2010: 12).

Isto significa dizer que a descrença com os valores democráticos pode gerar uma situação de anormalidade institucional, colocando em dúvida as instituições que amparam à democracia.

Os dados divulgados pelo Latinobarómetro sobre a adesão dos brasileiros à democracia são baixos. Nos anos de 1996, 2001, 2006, 2007 e 2008, o percentual de brasileiros que preferem a democracia a qualquer outra forma de regime político nunca ultrapassou os $50,0 \%$, respectivamente, com 50,0\%, 30,0\%, 46,0\%, $43,0 \%$ e $47,0 \%$ do total, indicando que a democracia não foi bem avaliada pelos brasileiros. Em pesquisa recente, a Latinobarómetro revelou que 46,0\% dos brasileiros não preferem a democracia como a melhor forma de governo.

Quanto a isto, Moisés (2005: 34) ressalta que no Brasil,

[...] a percepção negativa das instituições atravessa todos os segmentos de renda, escolaridade, idade e distribuição ecológica, chegando a influir sobre a disposição dos cidadãos para participar de processos políticos [...]. Moisés (2005: 34).

Se esse sentimento negativo sobre as instituições, em especial sobre a democracia, é generalizado entre os brasileiros, o que os parlamentares pensam da democracia? Sabemos que os deputados estaduais são atores que operam diretamente as instituições (Perissinotto e Braunert, 2006); além do mais, as 
suas opções políticas, quando comparadas aos demais atores, têm mais influencia sobre o sistema político vigente (Diáz, 2009: 19).

Seguindo essas colocações, convém perguntar: o que os membros das elites parlamentares das Assembleias Legislativas pensam da democracia? para eles a democracia é a melhor forma de governo? se sim, qual é o conteúdo desse apoio? se não, em que momento a democracia não é preferível? a opção ideológica influencia na percepção sobre a democracia? Essas são, entre muitas outras, algumas das questões com as quais os pesquisadores procuram estudar o significado do termo democracia.

Para elucidar empiricamente essas perguntas, o uso do questionário auto-administrado ${ }^{1}$ e estruturado foi a melhor técnica para apreender as opiniões dos deputados estaduais membros da elite parlamentar da Assembleia Legislativa do Estado de São Paulo². Já as percepções dos deputados estaduais paranaenses e catarinenses já foram coletas pelos pesquisadores associados ao Núcleo de Pesquisa em Sociologia Política Brasileira da Universidade Federal do Paraná e ao Departamento de Sociologia e Ciência Política da Universidade Federal de Santa Catarina com as pesquisas "As elites administrativas, parlamentares e partidárias do Paraná, 1995-2006" e "Elites políticas e a democracia: os valores políticos dos parlamentares catarinenses da $16^{\circ}$ Legislatura, 2007"3.

Com esse enfoque comparativo, este artigo tem o propósito de contribuir com os estudos sobre a democracia no Brasil e ele está assim organizado: na primeira parte, discutimos a estabilidade da democracia; na segunda, analisamos a adesão ao regime democrático e as situações em que os entrevistados admitem ou não o fim da democracia; na terceira, discutimos o conteúdo dessa adesão e na última parte, investigamos a opção ideológica do parlamentar relacionada ao regime democrático.

\footnotetext{
Segundo Babbie (2003), com o questionário auto-administrado, o entrevistado responde as perguntas sem a presença do entrevistador, possibilitando-o uma melhor organização do seu tempo, ou seja, ele poderá adequar o seu tempo para responder o questionário.

2 Os autores gostariam de agradecer os pesquisadores Renato Monseff Perissinotto (Núcleo de Pesquisa em Sociologia Política Brasileira) e Manuel Alcántara Sáez (Instituto de Iberoamérica da Universidad de Salamanca) por disponibilizarem e autorizarem o uso dos questionários das pesquisas "Quem governa? Mapeando as elites políticas paranaenses (1995-2002)" e "Élites Parlamentarias Latinoamericanas".

${ }^{3}$ Os bancos de dados dessas pesquisas podem ser encontrados gratuitamente no site do Consórcio de Informações Sociais, em < http://www.nadd.prp.usp.br/cis/index.a6spx>.
}

\section{Democracia na Visão dos Parlamentares Paulistas, Paranaenses e Catarinenses}

\section{Estabilidade democrática ${ }^{4}$}

Para os deputados estaduais paulistas, paranaenses e catarinenses o Brasil é uma democracia. Tal comprovação não foi surpresa para nós, pois atualmente é difícil encontrar um parlamentar que afirme o contrário. Embora os parlamentares digam isto, ainda é muito cedo para definir, a partir dessa afirmação, a que tipo de democracia eles estão se referindo. Constatado o reconhecimento de que o Brasil é uma democracia, vamos saber como está nas opiniões dos entrevistados a estabilidade desse regime.

Antes disto é importante distinguir as categorias Muito Estável e Bastante Estável, pois os termos Muito e Bastante podem provocar dúvidas no momento da leitura dos resultados. A diferença entre as duas categorias está na intensidade aferida de cada termo. No Dicionário de Língua Portuguesa Houaiss encontramos essa distinção: o termo Muito (advérbio) significa "exageradamente", "excessivamente", ou, ainda, "abundantemente"; enquanto o termo Bastante (também advérbio) expressa "quantidade suficiente", "satisfatoriamente", ou, ainda, "muito de maneira acima da média". Conhecido o discernimento entre os termos, a categoria Muito Estável agrega mais intensidade de aferição que a categoria Bastante Estável, pois Muito é mais forte que Bastante. Para observar essa diferença de intensidade, apresentamos a Tabela 1, que mostra os percentuais das opiniões dos parlamentares sobre a estabilidade da democracia.

$\mathrm{Na}$ Tabela 1 podemos ver que a maioria dos parlamentares paulistas pensa que a democracia está Bastante Estável, isto é, os deputados estaduais estão otimistas em avaliar o regime democrático e isto fica constatado no alto percentual da categoria $(73,4 \%)$. Chama atenção que para dois parlamentares a democracia brasileira é Pouco Estável (13,3\%). Essa percepção talvez possa ser um reflexo do alto percentual $(46,0 \%$ em 2010) de brasileiros que não acreditam na democracia como a melhor forma de governo.

As opiniões dos parlamentares paulistas informam que a democracia está Bastante Estável, mas quando se trata de identificar o grau de estabilidade democrática nas suas opiniões, o resultado obtido está um pouco

\footnotetext{
${ }^{4}$ A discussão sobre a estabilidade democrática somente ocorreu com as opiniões dos deputados estaduais paulistas, pois nas pesquisas auxiliares esse tema não foi perguntado entre os deputados estaduais paranaenses e catarinenses.
} 
Tabela 1. Estabilidade da democracia São Paulo, Paraná e Santa Catarina 2007-2009, 1995-2002 e 2007.

\begin{tabular}{lcccccc}
\hline \multirow{2}{*}{ Estabilidade } & \multicolumn{2}{c}{ Elite } & \multicolumn{2}{c}{ Elite } & \multicolumn{2}{c}{ Elite } \\
& \multicolumn{2}{c}{ ALESP } & \multicolumn{2}{c}{ ALEPR } & \multicolumn{2}{c}{ ALESC } \\
\cline { 2 - 7 } & N & $\%$ & N & $\%$ & N & $\%$ \\
\hline Muito estável & 2 & 13,3 &.$* *$ &. &. &. \\
Bastante estável & 11 & 73,4 &. &. &. &. \\
Pouco estável & 2 & 13,3 &. &. &. &. \\
Não é estável & $-*$ & - &. &. &. &. \\
Total & 15 & 100,0 &. &. &. &. \\
\hline
\end{tabular}

Fonte: Pesquisas Felisbino e Kerbauy (2009); Codato, Gouvêa e Perissinotto (2005); Venturini e Borba (2007). Obs.: *Sinal para indicar $\mathrm{N}$ e $\%$ igual a zero. **Sinal para indicar sem dados.

abaixo daqueles encontrados nas percepções dos membros das elites parlamentares de alguns países da América do Sul ${ }^{5}$. Entretanto, como veremos, o grau obtido com as opiniões dos nossos entrevistados paulistas é Alto.

Para calcular esse grau de estabilidade democrática usamos uma simples operação matemática, vejamos: a somatória das categorias Muito Estável e Bastante Estável pode indicar um grau Baixo (variando entre 0,00\%-39,99\%), Médio (40,00\%-79,99\%) ou Alto (80,00\%-100,00\%).

No caso das opiniões dos parlamentares sul-americanos, Felisbino (2008) ao analisar a democracia identificou que o Uruguai, Argentina e o Brasil são os países onde o grau de estabilidade democrática é Alto, isto significa que os valores encontrados, 97,80\%, 95,20\% e 93,30\%, respectivamente, oscilam no intervalo de $80,00 \%$ a $100,00 \%$. Por outro lado, o Paraguai e a Venezuela são os países que apresentam algumas dificuldades com a democracia, pois o grau de estabilidade democrática desses países, de acordo com a nossa classificação, é Médio, pois os valores obtidos foram $67,10 \%$ e $63,10 \%$, respectivamente. Já para o grupo paulista de parlamentares aqui analisado, o valor do grau da estabilidade democrática está um pouco abaixo do encontrado entre as elites parlamentares da América do Sul, com exceção dos resultados achados para os países do Paraguai e da Venezuela, mas esse grau, nas

\footnotetext{
${ }^{5}$ Embora seja uma comparação entre esferas governamentais (nacional versus estadual) e localizações (São Paulo/Paraná versus alguns países sul-americanos) diferentes, ela se justifica pela curiosidade em querer saber como está a democracia nas opiniões dos parlamentares de diferentes classes políticas em locais distintos.
}

opiniões dos deputados estaduais paulistas, é Alto, visto que o valor obtido foi de $86,70 \%$.

\section{Adesão à democracia}

Además de las actitudes hacia la democracia en general es importante que exista un apoyo firme a las instituciones que componen cualquier sistema político. Las instituciones importan y son un elemento central dentro de cualquier democracia ya que, en pocas palabras, influyen sobre 'las normas, las creencias y las acciones' y, por lo tanto, determinan los resultados. Margarita Corral, Instituto de Iberoamerica da Universidad de Salamanca (Espanha). (Corral, 2011: 5).

Quando se analisa a democracia de alguns países da América Latina, o que se busca saber é se ainda existe o desejo de voltar aos tempos dos militares no poder, pois pesquisas do Latinobarómetro já mostraram que os latino-americanos estariam dispostos a aceitar um regime autoritário se esse resolvesse os problemas que afligem a vida cotidiana dos cidadãos.

Ao contrário disto, verificamos uma ampla adesão dos deputados estaduais paulistas, paranaenses e catarinenses à democracia como a melhor forma de governo. Essa adesão, quando comparada com as pesquisas do Latinobarómetro, está em um patamar muito elevado. Para observar isto apresentamos a Tabela 2, que mostra os percentuais das opiniões dos latino-americanos, e a Tabela 3, que exibe as porcentagens das percepções dos parlamentares entrevistados que preferem a democracia a qualquer outro tipo de regime.

Como se pode observar na Tabela 2, menos da metade dos cidadãos do Paraguai, México e da Guatemala entrevistados, em 2010, consideram a democracia o melhor regime para se viver, com 49,0\%, $49,0 \%$ e $46,0 \%$ do total, respectivamente. No Brasil, a adesão à democracia pode ser considerada baixa. Segundo esse instituto de pesquisa, no ano de 2009, o percentual de brasileiros que preferem a democracia a qualquer outra forma de governo conseguiu ultrapassar os 50,0\%, pois nos anos de 2006, 2007 e 2008 o percentual foi de $46,0 \%, 43,0 \%$ e 47,0\%. Em 2010 esse percentual foi para $54,0 \%$, mas o apoio dos brasileiros à democracia, quando comparado com os nossos vizinhos bolivianos (68,0\%), ainda é baixo. Do outro lado, no topo da aceitação da democracia, estão os cidadãos da Venezuela e do Uruguai, com 84,0\% e $75,0 \%$, respectivamente.

Ao contrário do que ocorreu entre os latinoamericanos, em especial com os brasileiros entrevistados pelos pesquisadores associados ao Latinobarómetro, para os deputados estaduais dos Estados de Santa Catarina, São Paulo e Paraná e 
Tabela 2. Adesão à democracia** América Latina 2009 e 2010.

\begin{tabular}{|c|c|c|c|}
\hline \multirow{2}{*}{ País } & \multicolumn{2}{|c|}{ Ano } & \multirow{2}{*}{$\begin{array}{c}\neq \text { entre os } \\
\text { anos }\end{array}$} \\
\hline & 2009 & 2010 & \\
\hline Venezuela & $84,0 \%$ & $84,0 \%$ & $-*$ \\
\hline Uruguai & $82,0 \%$ & $75,0 \%$ & $-7,0 \%$ \\
\hline Rep. Dominicana & $67,0 \%$ & $63,0 \%$ & $-4,0 \%$ \\
\hline Bolívia & $71,0 \%$ & $68,0 \%$ & $-3,0 \%$ \\
\hline Costa Rica & $74,0 \%$ & $72,0 \%$ & $-2,0 \%$ \\
\hline Colômbia & $49,0 \%$ & $60,0 \%$ & $11,0 \%$ \\
\hline Argentina & $64,0 \%$ & $66,0 \%$ & $2,0 \%$ \\
\hline Nicarágua & $55,0 \%$ & $58,0 \%$ & $3,0 \%$ \\
\hline Panamá & $64,0 \%$ & $61,0 \%$ & $-3,0 \%$ \\
\hline Equador & $43,0 \%$ & $64,0 \%$ & $21,0 \%$ \\
\hline Paraguai & $46,0 \%$ & $49,0 \%$ & $3,0 \%$ \\
\hline Chile & $59,0 \%$ & $63,0 \%$ & $4,0 \%$ \\
\hline El Salvador & $68,0 \%$ & $59,0 \%$ & $-9,0 \%$ \\
\hline Brasil & $55,0 \%$ & $54,0 \%$ & $-1,0 \%$ \\
\hline Peru & $52,0 \%$ & $61,0 \%$ & $9,0 \%$ \\
\hline Honduras & $55,0 \%$ & $53,0 \%$ & $-2,0 \%$ \\
\hline México & $42,0 \%$ & $49,0 \%$ & $7,0 \%$ \\
\hline Guatemala & $42,0 \%$ & $46,0 \%$ & $4,0 \%$ \\
\hline
\end{tabular}

Fonte: Latinobarómetro. Obs.: *Sinal para indicar \% igual a zero. **Essa adesão diz respeito a seguinte pergunta no questionário do Latinobarómetro: ¿Con cuál de las siguientes frases está Ud. más de acuerdo? La democracia es preferible a cualquier otra forma de gobierno. En algunas circunstancias, un gobierno autoritario puede ser preferible a uno democrático. A la gente como uno, nos da lo mismo un régimen democrático que uno no democrático.

Tabela 3. Adesão à democracia São Paulo, Paraná e Santa Catarina 2007-2009, 1995-2002 e 2007.

\begin{tabular}{lcccccc}
\hline \multirow{2}{*}{ Adesão } & \multicolumn{2}{c}{ Elite } & \multicolumn{2}{c}{ Elite } & \multicolumn{2}{c}{ Elite } \\
& \multicolumn{2}{c}{ ALESP } & \multicolumn{2}{c}{ ALEPR } & \multicolumn{2}{c}{ ALESC } \\
\cline { 2 - 7 } & N & $\%$ & N & $\%$ & N & $\%$ \\
\hline A* & 14 & 93,3 & 59 & 92,2 & 34 & 97,1 \\
B & 1 & 6,7 & 5 & 7,8 & - & - \\
C & $-* *$ & - & - & - & - & - \\
D & - & - & - & - & 1 & 2,9 \\
Total & 15 & 100,0 & 64 & 100,0 & 35 & 100,0 \\
\hline
\end{tabular}

Fonte: Pesquisas Felisbino e Kerbauy (2009); Codato, Gouvêa e Perissinotto (2005); Venturini e Borba (2007). Obs.: *A = A democracia é sempre a melhor forma de governo; $\mathrm{B}=\mathrm{A}$ democracia às vezes é a melhor forma de governo; $\mathrm{C}=\mathrm{A}$ democracia nunca é a melhor forma de governo e $\mathrm{D}=\mathrm{E}$ indiferente ter ou não uma democracia. **Sinal para indicar $\mathrm{N}$ e \% igual a zero. a adesão a essa forma de governo abrange quase todos os membros das elites parlamentares dessas unidades da Federação, com, respectivamente, $97,1 \%$, $93,3 \%$ e $92,2 \%$ do total. Isto significa, segundo as informações expostas na Tabela 3 , que a volta aos anos de chumbo está longe de acontecer. A tabela ainda mostra que somente um parlamentar da elite paulista disse que a democracia às vezes é a melhor forma de governo, enquanto no seleto grupo da casa Legislativa paranaense são cinco os parlamentares que disseram o mesmo.

As informações apresentadas na Tabela 3 não nos dizem nada a respeito de quão intensamente os parlamentares entrevistados aderem ao regime democrático. Para tentar verificar essa intensidade, os parlamentares tiveram que Concordar ou Discordar de algumas afirmações que justificariam o fim do regime democrático. A Tabela 4 exibe os percentuais em que o fim da democracia seria ou não aceitável nas situações apresentadas aos entrevistados.

A Tabela 4 reforça as informações expostas na tabela anterior, pois podemos observar uma forte adesão dos deputados estaduais à democracia. Isto se confirma porque em nenhuma das situações dadas aos membros das elites parlamentares a opção Concorda foi aceita pela maioria dos grupos analisados, salvo na última situação. O que mais estimulam os paulistas a aceitarem o fim da democracia foram as situações que envolvem a corrupção generalizada $(20,0 \%)$, a ameaça ao Estado pelo crime organizado $(20,0 \%)$ e a ameaça aos valores morais e religiosos $(13,3 \%)$. Entre os deputados estaduais paranaenses, a ameaça ao Estado pelo crime organizado, a ameaça aos valores morais e religiosos, a ameaça à propriedade privada, a corrupção generalizada na estrutura estatal e ameaça à ordem pública em função de crise econômica foram as situações que mais motivam esses entrevistados a aceitarem o fim desse regime, com 39,7\%, 39,1\%, $38,1 \%, 37,5 \%$ e $32,8 \%$, respectivamente. O que mais encorajam os catarinenses a aceitarem a interrupção da democracia foram as situações que envolvem a ameaça à propriedade privada e a ameaça ao Estado pelo crime organizado, com escores de 22,9\% e 20,0\% cada um. Entretanto, nos três universos analisados por nós, alguns parlamentares disseram concordar com o fim dessa forma de governo e as fontes de coleta de dados utilizadas neste artigo não permitem conhecer os possíveis motivos dessas percepções.

Os dados apresentados da Tabela 4 ainda chamam atenção para duas situações. A primeira foi saber que a ameaça à propriedade privada é um problema para interromper o regime democrático, sobretudo para os deputados estaduais do Paraná, onde o escore é maior. Essa preocupação é significativa para os paranaenses, 
Tabela 4. Concorda ou discorda com o fim da democracia São Paulo, Paraná e Santa Catarina 2007-2009, 1995-2002 e 2007.

\begin{tabular}{|c|c|c|c|c|c|c|c|c|c|}
\hline \multirow{2}{*}{ Situação } & \multicolumn{2}{|c|}{ Elite ALESP } & \multirow{2}{*}{ Total } & \multicolumn{2}{|c|}{ Elite ALEPR } & \multirow{2}{*}{ Total } & \multicolumn{2}{|c|}{ Elite ALESC } & \multirow{2}{*}{ Total } \\
\hline & $\mathbf{C}^{* *}$ & D & & C & D & & C & D & \\
\hline $\mathrm{A}^{*}$ & $-* * *$ & $\begin{array}{c}100,0 \% \\
(15)\end{array}$ & $\begin{array}{c}100,0 \% \\
(15)\end{array}$ & $\begin{array}{c}38,1 \% \\
(24)\end{array}$ & $\begin{array}{c}61,9 \% \\
(40)\end{array}$ & $\begin{array}{c}100,0 \% \\
(64)\end{array}$ & $\begin{array}{c}22,9 \% \\
(8)\end{array}$ & $\begin{array}{c}68,6 \% \\
(24)\end{array}$ & $\begin{array}{c}91,5 \% \\
(32)\end{array}$ \\
\hline B & $\begin{array}{c}13,3 \% \\
(2)\end{array}$ & $\begin{array}{c}86,7 \% \\
(13)\end{array}$ & $\begin{array}{c}100,0 \% \\
(15)\end{array}$ & $\begin{array}{c}39,1 \% \\
(25)\end{array}$ & $\begin{array}{l}59,3 \% \\
(38)\end{array}$ & $\begin{array}{c}98,4 \% * * * * \\
(63)\end{array}$ & $\begin{array}{l}17,2 \% \\
(6)\end{array}$ & $\begin{array}{c}74,3 \% \\
(26)\end{array}$ & $\begin{array}{c}91,5 \% \\
(32)\end{array}$ \\
\hline $\mathrm{C}$ & $\begin{array}{c}13,3 \% \\
(2)\end{array}$ & $\begin{array}{c}86,7 \% \\
(13)\end{array}$ & $\begin{array}{c}100,0 \% \\
(15)\end{array}$ & $\begin{array}{l}32,8 \% \\
(21)\end{array}$ & $\begin{array}{c}65,6 \% \\
42\end{array}$ & $\begin{array}{l}98,4 \% \\
(63)\end{array}$ & $\begin{array}{l}17,2 \% \\
(6)\end{array}$ & $\begin{array}{c}74,3 \% \\
(26)\end{array}$ & $\begin{array}{c}91,5 \% \\
(32)\end{array}$ \\
\hline $\mathrm{D}$ & $\begin{array}{c}20,0 \% \\
(3)\end{array}$ & $\begin{array}{c}80,0 \% \\
(12)\end{array}$ & $\begin{array}{c}100,0 \% \\
(15)\end{array}$ & $\begin{array}{c}37,5 \% \\
(24)\end{array}$ & $\begin{array}{c}60,9 \% \\
(39)\end{array}$ & $\begin{array}{l}98,4 \% \\
(63)\end{array}$ & $\begin{array}{c}14,3 \% \\
(5)\end{array}$ & $\begin{array}{c}80,0 \% \\
(28)\end{array}$ & $\begin{array}{c}94,3 \% \\
(33)\end{array}$ \\
\hline $\mathrm{E}$ & $\begin{array}{c}20,0 \% \\
(3)\end{array}$ & $\begin{array}{c}80,0 \% \\
(12)\end{array}$ & $\begin{array}{c}100,0 \% \\
(15)\end{array}$ & $\begin{array}{l}39,7 \% \\
(25)\end{array}$ & $\begin{array}{c}60,3 \% \\
(39)\end{array}$ & $\begin{array}{c}100,0 \% \\
(64)\end{array}$ & $\begin{array}{l}20,1 \% \\
(7)\end{array}$ & $\begin{array}{c}71,4 \% \\
(25)\end{array}$ & $\begin{array}{c}91,5 \% \\
(32)\end{array}$ \\
\hline $\mathrm{F}$ & $\begin{array}{c}6,7 \% \\
(1)\end{array}$ & $\begin{array}{l}93,3 \% \\
(14)\end{array}$ & $\begin{array}{c}100,0 \% \\
(15)\end{array}$ & $\begin{array}{c}20,3 \% \\
(13)\end{array}$ & $\begin{array}{c}78,1 \% \\
(50)\end{array}$ & $\begin{array}{l}98,4 \% \\
(63)\end{array}$ & $\begin{array}{c}11,4 \% \\
(4)\end{array}$ & $\begin{array}{c}71,4 \% \\
(25)\end{array}$ & $\begin{array}{c}82,8 \% \\
(29)\end{array}$ \\
\hline G & $\begin{array}{c}73,3 \% \\
(11)\end{array}$ & $\begin{array}{l}26,7 \% \\
(4)\end{array}$ & $\begin{array}{c}100,0 \% \\
(15)\end{array}$ & $\begin{array}{c}57,8 \% \\
(37)\end{array}$ & $\begin{array}{c}40,6 \% \\
(26)\end{array}$ & $\begin{array}{c}98,4 \% \\
(63)\end{array}$ & $\begin{array}{c}91,5 \% \\
(32)\end{array}$ & $\begin{array}{l}5,7 \% \\
(2)\end{array}$ & $\begin{array}{c}97,1 \% \\
(34)\end{array}$ \\
\hline
\end{tabular}

Fonte: Pesquisas Felisbino e Kerbauy (2009); Codato, Gouvêa e Perissinotto (2005); Venturini e Borba (2007). Obs.: *A = Ameaça à propriedade privada; $\mathrm{B}=$ Ameaça aos valores morais e religiosos; $\mathrm{C}=$ Ameaça à ordem pública em função de crise econômica; $\mathrm{D}=$ Corrupção generalizada; $\mathrm{E}=$ Ameaça ao Estado pelo crime organizado; $\mathrm{F}=$ Quebra da hierarquia das instituições militares e $\mathrm{G}=$ Não é aceitável o fim da democracia. $* * \mathrm{C}=\mathrm{Concorda}$ e $\mathrm{D}=$ Discorda. $* * *$ Sinal para indicar \% e $\mathrm{N}$ igual a zero. ****Total que não atingiu 100,0\% diz respeito às opções NR/NS.

pois nesse Estado ocorrem muitas disputas por terras, o que pode ter provocado essa inquietação dos parlamentares. A segunda compartilha com alguns estudos sobre as elites políticas e a democracia (Moisés, 2005, 2010; Lima e Cheibud, 1996), que constataram, que após um árduo período de ditadura, muitos entrevistados (50 paranaenses, 25 catarinenses e 14 paulistas) não acharam que se deve interromper a democracia por uma eventual crise no interior da caserna. Isto significa dizer que uma possível rebelião militar não constitui uma preocupação para os parlamentares entrevistados.

Também constatamos que os dados expostos na Tabela 4 para as elites parlamentares paulista e paranaense apresentam certa coerência nas respostas dos deputados estaduais, isto significa dizer que ao escolherem a opção Discordar na última situação (Não é aceitável o fim da democracia), o valor de $\mathrm{N}$ é superior às demais opções de concordância (exceto para última assertiva), onde o escore de $\mathrm{N}$ é inferior. Com relação aos dados do seleto grupo parlamentar de Santa Catarina, verificamos que há uma incongruência nas respostas dos entrevistados, pois alguns deles, por exemplo, em ameaça à propriedade privada podem aceitar a suspensão da democracia, mas também podem concordar que o fim desse regime não é aceitável.

\section{Conteúdo do apoio democrático}

Até aqui constatamos que os parlamentares dos três Estados apóiam fortemente a democracia, entretanto não conhecemos o conteúdo desse apoio. Para identificar o conteúdo de adesão, um dos meios utilizados foi apresentar aos membros das elites parlamentares algumas questões que abordassem temas da igualdade social e da participação política, pois são assuntos que circunscrevem os princípios de um regime democrático. O que se busca é conhecer as opiniões dos entrevistados sobre as medidas que visem não apenas fortalecer o lado social da democracia (o crescimento da igualdade social) como também o outro lado, o político (o aumento da participação da atividade política).

Com relação ao primeiro tema, Perissinotto e Braunert (2006) ressaltam que a igualdade social é um assunto relevante na análise das percepções dos parlamentares sobre a democracia, pois para os entrevistados existem alguns obstáculos, por exemplo, a desigualdade da renda, a deficiência educacional da maioria dos cidadãos etc, que poderiam ameaçar a consolidação desse regime. Nesse sentido, para conhecer as opiniões dos deputados estaduais sobre políticas sociais, os entrevistados tiveram que se posicionar concordando ou discordando com algumas políticas que poderiam contribuir para superar tais obstáculos e para dirimir a desigualdade social entre 
Tabela 5. Concorda ou discorda com a promoção de políticas igualitárias São Paulo, Paraná e Santa Catarina 2007-2009, 1995-2002 e 2007.

\begin{tabular}{|c|c|c|c|c|c|c|c|c|c|}
\hline \multirow{2}{*}{$\begin{array}{l}\text { Igualdade } \\
\text { social }\end{array}$} & \multicolumn{2}{|c|}{ Elite ALESP } & \multirow{2}{*}{ Total } & \multicolumn{2}{|c|}{ Elite ALEPR } & \multirow{2}{*}{ Total } & \multicolumn{2}{|c|}{ Elite ALESC } & \multirow{2}{*}{ Total } \\
\hline & $C_{* *}^{* *}$ & D & & C & D & & $\mathrm{C}$ & D & \\
\hline $\mathrm{A}^{*}$ & $\begin{array}{c}100,0 \% \\
(15)\end{array}$ & $-* * *$ & $\begin{array}{c}100,0 \% \\
(15)\end{array}$ & $\begin{array}{c}89,0 \% \\
(57)\end{array}$ & $\begin{array}{c}11,0 \% \\
(7)\end{array}$ & $\begin{array}{c}100,0 \% \\
(64)\end{array}$ & $\begin{array}{c}88,6 \% \\
(31)\end{array}$ & $\begin{array}{l}11,4 \% \\
(4)\end{array}$ & $\begin{array}{c}100,0 \% \\
(35)\end{array}$ \\
\hline B & $\begin{array}{c}100,0 \% \\
(15)\end{array}$ & - & $\begin{array}{c}100,0 \% \\
(15)\end{array}$ & $\begin{array}{c}95,3 \% \\
(61)\end{array}$ & $\begin{array}{c}4,7 \% \\
(3)\end{array}$ & $\begin{array}{l}100,0 \% \\
(64)\end{array}$ & $\begin{array}{c}97,1 \% \\
(34)\end{array}$ & - & $\begin{array}{c}97,1 \% \\
(34)\end{array}$ \\
\hline $\mathrm{C}$ & $\begin{array}{c}93,3 \% \\
(14)\end{array}$ & $\begin{array}{c}6,7 \% \\
(1)\end{array}$ & $\begin{array}{c}100,0 \% \\
(15)\end{array}$ & $\begin{array}{c}78,1 \% \\
(50)\end{array}$ & $\begin{array}{c}21,9 \% \\
14\end{array}$ & $\begin{array}{c}100,0 \% \\
(64)\end{array}$ & $\begin{array}{c}68,6 \% \\
(24)\end{array}$ & $\begin{array}{l}28,5 \% \\
(10)\end{array}$ & $\begin{array}{l}97,1 \% \\
(34)\end{array}$ \\
\hline $\mathrm{D}$ & $\begin{array}{c}93,3 \% \\
(14)\end{array}$ & $\begin{array}{l}6,7 \% \\
(1)\end{array}$ & $\begin{array}{c}100,0 \% \\
(15)\end{array}$ & $\begin{array}{c}60,9 \% \\
(39)\end{array}$ & $\begin{array}{l}37,5 \\
(24)\end{array}$ & $\begin{array}{c}98,4 \% * * * * \\
(63)\end{array}$ & $\begin{array}{c}54,3 \% \\
(19)\end{array}$ & $\begin{array}{c}40,0 \% \\
(14)\end{array}$ & $\begin{array}{c}94,3 \% \\
(32)\end{array}$ \\
\hline $\mathrm{E}$ & $\begin{array}{c}66,6 \% \\
(10)\end{array}$ & $\begin{array}{c}33,3 \% \\
(5)\end{array}$ & $\begin{array}{c}100,0 \% \\
(15)\end{array}$ & $\begin{array}{c}51,6 \% \\
(33)\end{array}$ & $\begin{array}{l}48,4 \% \\
(31)\end{array}$ & $\begin{array}{c}100,0 \% \\
(64)\end{array}$ & $\begin{array}{c}71,4 \% \\
(25)\end{array}$ & $\begin{array}{l}25,7 \% \\
(9)\end{array}$ & $\begin{array}{c}97,1 \% \\
(32)\end{array}$ \\
\hline $\mathrm{F}$ & $\begin{array}{c}66,6 \% \\
(10)\end{array}$ & $\begin{array}{c}33,3 \% \\
(5)\end{array}$ & $\begin{array}{l}100,0 \% \\
(15)\end{array}$ & . & $* * * * *$ & . & . & . & . \\
\hline G & $\begin{array}{c}60,0 \% \\
(9)\end{array}$ & $\begin{array}{c}40,0 \% \\
(6)\end{array}$ & $\begin{array}{l}100,0 \% \\
(15)\end{array}$ & . & . & . & . & . & . \\
\hline
\end{tabular}

Fonte: Pesquisas Felisbino e Kerbauy (2009); Codato, Gouvêa e Perissinotto (2005); Venturini e Borba (2007). Obs.: *A = Sistema universitário gratuito; $\mathrm{B}=$ Universalização da saúde pública; $\mathrm{C}=$ Renda mínima para todos; $\mathrm{D}=\mathrm{Cotas}$ para negros nas universidades públicas; $\mathrm{E}=$ Reforma agrária em terras produtivas ou não; $\mathrm{F}=$ Legalização da prática do aborto e $\mathrm{G}=\mathrm{União}$ civil de pessoas do mesmo sexo. $* * \mathrm{C}=$ Concorda e $\mathrm{D}=$ Discorda. $* * *$ Sinal para indicar $\%$ e $\mathrm{N}$ igual a zero. $* * * *$ Total que não atingiu $100,0 \%$ diz respeito às opções NR/NS. ***** Sinal para indicar sem dados.

os grupos sociais. Com esse propósito, a Tabela 5 apresenta os percentuais das opiniões dos deputados estaduais com relação às políticas sociais igualitárias.

Depreendemos da matriz de dados acima que essas políticas despertaram o espírito igualitário dos nossos entrevistados. No interior da elite parlamentar paulista, merece destaque as políticas que focam o sistema universitário gratuito, a universalização da saúde, a renda mínima e a cotas para negros, pois foram, por sua vez, as políticas que mais obtiveram adesão dos entrevistados, com 100,0\%, 100,0\%, $93,3 \%$ e 93,3\%, respectivamente. Já algumas políticas que dividem a opinião dos cidadãos no seu dia-a-dia também obtiveram apoio de alguns parlamentares, por exemplo, a legalização da prática do aborto, a reforma agrária em terras produtivas e improdutivas e a união civil de pessoas do mesmo sexo alcançaram uma adesão de $66,6 \%, 66,6 \%$ e $60,0 \%$, respectivamente, dos entrevistados. Entre os membros pertencentes à elite parlamentar paranaense, a universalização da saúde, o sistema universitário gratuito e a renda mínima foram as políticas que mais chamaram atenção dos membros desse seleto grupo, respectivamente, com $95,3 \%, 89,0 \%$ e $78,1 \%$ do total. No seio da elite parlamentar catarinense, merece destacar a universalização da saúde pública $(97,1 \%)$ e o sistema universitário gratuito $(88,6 \%)$, pois para os membros desse seleto grupo político essas políticas buscam, de certa forma, equacionar o problema da desigualdade social.

O que chamou a nossa atenção foi o alto percentual favorável pela reforma agrária, tanto em terras improdutivas quanto produtivas. Como foi dito anteriormente, no caso paranaense, consequentemente para o catarinense, esse fato está relacionando com a enorme quantidade de propriedades rurais, que, por sua vez, vem provocando muitas disputas agrárias. Com relação a isto, Elisa Reis (2000) vê que a reforma agrária é vista pelos membros das elites como uma política pública essencial para o combate à desigualdade entre os grupos sociopolíticos. Tal raciocínio pode ser notado com os altos percentuais encontrados entre os catarinenses e paulistas, enquanto com os paranaenses não podemos dizer o mesmo, pois eles estão divididos em apoiar ou não a reforma agrária.

Dando continuidade à caracterização do conteúdo, o próximo passo foi conhecer as opiniões dos parlamentares sobre o tema da participação política. Para apreender tais opiniões, os parlamentares tiveram que se posicionar concordando ou discordando com algumas políticas que poderiam contribuir para o alargamento das esferas de participação dos cidadãos. A Tabela 6 apresenta os percentuais das opiniões dos 
Tabela 6. Concorda ou discorda com a ampliação da participação política São Paulo, Paraná e Santa Catarina 2007-2009, 1995-2002 e 2007.

\begin{tabular}{|c|c|c|c|c|c|c|c|c|c|}
\hline \multirow{2}{*}{$\begin{array}{c}\text { Participação } \\
\text { política }\end{array}$} & \multicolumn{2}{|c|}{ Elite ALESP } & \multirow{2}{*}{ Total } & \multicolumn{2}{|c|}{ Elite ALEPR } & \multirow{2}{*}{ Total } & \multicolumn{2}{|c|}{ Elite ALESC } & \multirow{2}{*}{ Total } \\
\hline & $\mathbf{C}^{* *}$ & D & & C & D & & C & D & \\
\hline $\mathrm{A}^{*}$ & $\begin{array}{c}100,0 \% \\
(15)\end{array}$ & $-* * *$ & $\begin{array}{c}100,0 \% \\
(15)\end{array}$ & $\begin{array}{l}95,2 \% \\
(61)\end{array}$ & $\begin{array}{c}1,6 \% \\
(1)\end{array}$ & $\begin{array}{c}96,8 \% * * * * \\
(62)\end{array}$ & $\begin{array}{l}97,1 \% \\
(34)\end{array}$ & - & $\begin{array}{c}97,1 \% \\
(34)\end{array}$ \\
\hline $\mathrm{B}$ & $\begin{array}{l}46,7 \% \\
(7)\end{array}$ & $\begin{array}{l}53,3 \% \\
(8)\end{array}$ & $\begin{array}{c}100,0 \% \\
(15)\end{array}$ & $\begin{array}{l}59,4 \% \\
(38)\end{array}$ & $\begin{array}{c}23,4 \% \\
15\end{array}$ & $\begin{array}{l}82,8 \% \\
(53)\end{array}$ & $\begin{array}{c}40,0 \% \\
(14)\end{array}$ & $\begin{array}{l}45,8 \% \\
(16)\end{array}$ & $\begin{array}{c}85,8 \% \\
(30)\end{array}$ \\
\hline $\mathrm{C}$ & $\begin{array}{l}53,3 \% \\
\quad(8)\end{array}$ & $\begin{array}{c}46,7 \% \\
(7)\end{array}$ & $\begin{array}{c}100,0 \% \\
(15)\end{array}$ & $\begin{array}{c}70,3 \% \\
(45)\end{array}$ & $\begin{array}{c}17,2 \% \\
(11)\end{array}$ & $\begin{array}{c}87,5 \% \\
(56)\end{array}$ & $\begin{array}{c}40,0 \% \\
(14)\end{array}$ & $\begin{array}{c}31,5 \% \\
(11)\end{array}$ & $\begin{array}{c}71,5 \% \\
(25)\end{array}$ \\
\hline $\mathrm{D}$ & $\begin{array}{c}46,7 \% \\
(7)\end{array}$ & $\begin{array}{l}53,3 \% \\
(8)\end{array}$ & $\begin{array}{c}100,0 \% \\
(15)\end{array}$ & $\begin{array}{c}67,2 \% \\
(43)\end{array}$ & $\begin{array}{c}23,4 \% \\
(15)\end{array}$ & $\begin{array}{c}90,6 \% \\
(58)\end{array}$ & $\begin{array}{c}54,3 \% \\
(19)\end{array}$ & $\begin{array}{c}28,6 \% \\
(10)\end{array}$ & $\begin{array}{c}82,9 \% \\
(29)\end{array}$ \\
\hline $\mathrm{E}$ & $\begin{array}{c}20,0 \% \\
(3)\end{array}$ & $\begin{array}{c}80,0 \% \\
(12)\end{array}$ & $\begin{array}{c}100,0 \% \\
(15)\end{array}$ & $\begin{array}{c}65,6 \% \\
(42)\end{array}$ & $\begin{array}{c}29,7 \% \\
19\end{array}$ & $\begin{array}{c}95,3 \% \\
(61)\end{array}$ & $\begin{array}{c}60,0 \% \\
(21)\end{array}$ & $\begin{array}{l}17,2 \% \\
(6)\end{array}$ & $\begin{array}{c}77,2 \% \\
(27)\end{array}$ \\
\hline
\end{tabular}

Fonte: Pesquisas Felisbino e Kerbauy (2009); Codato, Gouvêa e Perissinotto (2005); Venturini e Borba (2007). Obs.: *A = Participação do cidadão pelo voto; $\mathrm{B}=$ Participação do cidadão pelo plebiscito; $\mathrm{C}=$ Participação do cidadão pelos conselhos gestores; $\mathrm{D}=\mathrm{Participação}$ do cidadão pelo orçamento participativo e $\mathrm{E}=$ Participação direta do cidadão nos assuntos públicos. $* * \mathrm{C}=$ Concorda e $\mathrm{D}=\mathrm{Discorda}$.

***Sinal para indicar \% e N igual a zero. ****Total que não atingiu 100,0\% diz respeito às opções NR/NS.

parlamentares com relação à ampliação participativa do cidadão.

O que se vê na Tabela 6 é que entre os parlamentares paulistas a ideia de democracia está fortemente vinculada ao campo eleitoral, isto significa dizer que só existe esse regime se houver a participação do cidadão pelo voto $(100,0 \%)$. Por outro lado, a visão democrática defendida por Jean-Jacques Rousseau, isto é, uma participação direta do cidadão em todas as decisões, não é aceita pela grande maioria dos parlamentares do Estado de São Paulo, somente três concordaram com tal participação. Para as demais formas possíveis de participação, os conselhos gestores $(53,3 \%)$, o plebiscito $(46,7 \%)$ e o orçamento participativo $(46,7 \%)$, foram avaliadas por alguns parlamentares paulistas favoravelmente, podendo ser utilizadas em conjunto à visão eleitoral do grupo por nós estudado. No interior do grupo paranaense também podemos observar que, na concepção dos parlamentares, o termo democracia está intimamente associado ao processo eleitoral, com $95,2 \%$ apoiando essa participação. O que chamou a nossa atenção foram os altos percentuais dos que concordam nas demais formas possíveis de participação, por exemplo, $65,6 \%$ dos entrevistados paranaenses concordaram com a participação direta dos cidadãos no processo de tomada de decisão. Os conselhos gestores (70,3\%), o orçamento participativo $(67,2 \%)$ e o plebiscito $(59,4 \%)$ são outras formas de participação aceitas por alguns deputados estaduais paranaenses. Já para os parlamentares do Estado de Santa Catarina, a Tabela 6 nos revela que eles comungam fortemente $(97,1 \%)$ com a ideia de que a democracia só existe se os cidadãos escolherem seus representantes por meio do voto. Com relação às outras formas possíveis de participação, eles vêem outros mecanismos institucionais que possibilitam ampliar a participação da população nos assuntos públicos.

O conteúdo do apoio ao regime democrático mostrou-se distribuído nas diversas formas de políticas sociais e de participação, mas a percepção de democracia dos deputados estaduais está vinculada à criação de alguns serviços básicos e à participação dos cidadãos pelo voto.

\section{Esquerda, centro, direita e democracia}

Até aqui identificamos que a democracia está atrelada à criação de alguns serviços ditos básicos e à participação dos brasileiros via voto, são essas duas características que dão um caráter especial à noção de democracia defendida pelos deputados estaduais. Todavia, a opção ideológica influencia a percepção dos parlamenatres sobre a democracia? ter ou não uma posição pode comprometer a adesão à democracia? Para responder essas perguntas, utilizamos uma escala ideológica de sete posições ${ }^{6}$ (1 representa a posição mais à esquerda e 7 mais à direita) para conhecer o posicionamento ideológico dos parlamentares dos três Estados. (Figura 1).

A escala utilizada nesse artigo é um instrumento manipulado por muitos pesquisadores (Sáez, 2008,

\footnotetext{
${ }^{6}$ Cada uma das opções dessa escala representa uma posição ideológica, mas elas não foram mostradas na questão do nosso questionário auto-administrado, pois acreditamos que poderia intimidar os entrevistados no momento da escolha.
} 
2004; Zucco Júnior, 2009) e seu uso gera algumas controvérsias na apreensão da opção ideológica do parlamentar, pois o entrevistado pode mentir sobre a sua verdadeira posição no espaço ideológico (Perissinotto e Braunert, 2007, 2006; Sáez, 2004). Sabendo desse risco, resolvemos utilizá-la, pois no momento foi a melhor ferramenta que encontramos para identificar a relação entre opção ideológica e democracia. Para tanto, antes é interessante conhecer como o deputado estadual se posiciona na escala apresentada a ele, pois diante das sete opções ele tem que escolher uma que satisfaça as suas necessidades ideológicas. Os resultados encontram-se nas Tabelas 7 e 8 .

Podemos observar na Tabela 7 que muitos parlamentares se dizem de esquerda, mas quando olhamos para a Tabela 8 notamos que boa parte dos paulistas, paranaenses e catarinenses está entre as opções de centro-esquerda, esquerda e também de centro, mas centro-esquerda tornou-se a localização da maioria dos deputados estaduais dos três grupos analisadas por nós. Quanto a isto, compartilhamos com a ideia exposta por Perissinotto e Braunert (2007: 205) quando eles afirmam que ao escolherem o centro-esquerda, ela se torna

[...] uma posição que não se compromete com a insensibilidade social da direita nem com as posições 'extremadas' e 'ultrapassadas' da esquerda [...]. No geral, os atores políticos evitam posições polêmicas, ou seja: [...] ser (ou parecer) de esquerda radical não é bom, mas pior ainda é ser (ou parecer) de direita. (Rodrigues, 1987: 100).

Então, podemos dizer que ser de centro-esquerda significa ter um posicionamento que não fere estrategicamente quem pertence a um partido de esquerda ou de direita. Embora os dados mostrem uma dominância da ideologia de esquerda nos três grupos analisados, não podemos afirmar que no interior das casas Legislativas exista uma prática política pautada em orientações esquerdistas.

Com esse breve retrato ideológico dos deputados estaduais, nesse momento podemos analisar as percepções dos parlamentares entrevistados que preferem a democracia a qualquer outro tipo de regime, segundo as suas escolhas ideológicas. Para identificar isto, cruzamos as variáveis adesão à democracia e opção ideológica agregada e a Tabela 9 traz essas informações.

Na Tabela 9 percebemos que os deputados estaduais que se dizem de esquerda tendem aderir mais facilmente a esse regime político. Encontramos associação significativa entre a opção ideológica do parlamentar e o fato de apoiar ou não a democracia somente com o grupo paulista, enquanto nos outros

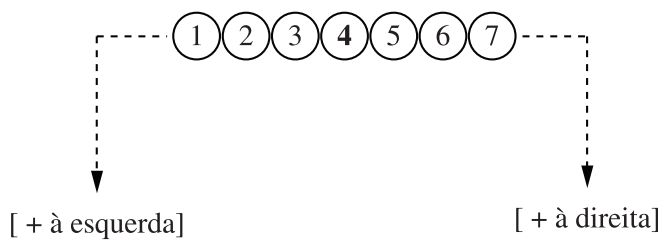

Figura 1. Representação escalar da opção ideológica.

Tabela 7. Opção ideológica agregada São Paulo, Paraná e Santa Catarina 2007-2009, 1995-2002 e 2007.

\begin{tabular}{|c|c|c|c|c|c|c|}
\hline \multirow[t]{2}{*}{ Opção } & \multicolumn{2}{|c|}{$\begin{array}{c}\text { Elite } \\
\text { ALESP }\end{array}$} & \multicolumn{2}{|c|}{$\begin{array}{c}\text { Elite } \\
\text { ALEPR }\end{array}$} & \multicolumn{2}{|c|}{$\begin{array}{c}\text { Elite } \\
\text { ALESC }\end{array}$} \\
\hline & $\mathbf{N}$ & $\%$ & $\mathbf{N}$ & $\%$ & $\mathbf{N}$ & $\%$ \\
\hline Esquerda & 12 & 80,0 & 33 & 51,6 & 23 & 65,7 \\
\hline Centro & 1 & 6,7 & 16 & 25,0 & 7 & 20,0 \\
\hline Direita & 2 & 13,3 & 12 & 18,8 & 5 & 14,3 \\
\hline Total & 15 & 100,0 & 61 & $95,3 *$ & 35 & 100,0 \\
\hline
\end{tabular}

Fonte: Pesquisas Felisbino e Kerbauy (2009); Codato, Gouvêa e Perissinotto (2005); Venturini e Borba (2007). Obs.: *Total que não atingiu 100,0\% diz respeito às opções NR/NS

Tabela 8. Opção ideológica São Paulo, Paraná e Santa Catarina 2007-2009, 1995-2002 e 2007.

\begin{tabular}{lcccccc}
\hline \multirow{2}{*}{\multicolumn{1}{c}{ Opção }} & \multicolumn{2}{c}{$\begin{array}{c}\text { Elite } \\
\text { ALESP }\end{array}$} & \multicolumn{2}{c}{$\begin{array}{c}\text { Elite } \\
\text { ALEPR }\end{array}$} & \multicolumn{2}{c}{$\begin{array}{c}\text { Elite } \\
\text { ALESC }\end{array}$} \\
\cline { 2 - 8 } & $\mathbf{N}$ & $\boldsymbol{\%}$ & $\mathbf{N}$ & $\boldsymbol{\%}$ & $\mathbf{N}$ & $\boldsymbol{\%}$ \\
\hline Extrema-esquerda & 2 & 13,3 & 3 & 4,7 & - & - \\
Esquerda & 4 & 26,7 & 12 & 18,8 & 7 & 20,0 \\
Centro-esquerda & 6 & 40,0 & 18 & 28,1 & 15 & 42,9 \\
Centro & 1 & 6,7 & 16 & 25,0 & 7 & 20,0 \\
Centro-direita & 2 & 13,2 & 9 & 14,1 & 6 & 17,1 \\
Direita & - & - & 1 & 1,6 & - & - \\
Extrema-direita & $-*$ & - & 2 & 4,7 & - & - \\
Total & 15 & 100,0 & 61 & $95,3 * *$ & 35 & 100,0 \\
\hline
\end{tabular}

Fonte: Pesquisas Felisbino e Kerbauy (2009); Codato, Gouvêa e Perissinotto (2005); Venturini e Borba (2007). Obs.: *Sinal para indicar \% e N igual a zero.**Total que não atingiu $100,0 \%$ diz respeito às opções NR/NS.

universos (paranaense e catarinense) temos que fazer duas considerações.

A primeira é que o Sig. para o grupo catarinense (Tabela 10) foi elevado devido ao número pequeno da $\operatorname{amostra}(\mathrm{N}=35)$ e isto pode ter elevado essa estatística. Nesse caso, os estatísticos recomendam uma atenção ao coeficiente de contingência, pois 
Tabela 9. Adesão à democracia, segundo a opção ideológica agregada São Paulo, Paraná e Santa Catarina 2007-2009, 1995-2002 e 2007.

\begin{tabular}{|c|c|c|c|c|c|}
\hline \multirow{2}{*}{ Elites } & \multirow{2}{*}{$\begin{array}{c}\text { Adesão à } \\
\text { democracia }\end{array}$} & \multicolumn{3}{|c|}{ Opção } & \multirow{2}{*}{ Total } \\
\hline & & Esquerda & Centro & Direita & \\
\hline \multirow[t]{4}{*}{ ALESP } & $\mathrm{A}^{*}$ & $\begin{array}{c}85,7 \% \\
(12)\end{array}$ & $\begin{array}{l}7,1 \% \\
(1)\end{array}$ & $\begin{array}{l}7,1 \% \\
(1)\end{array}$ & $\begin{array}{l}100,0 \% \\
(14)\end{array}$ \\
\hline & B & - & - & $\begin{array}{l}100,0 \% \\
\text { (1) }\end{array}$ & $\begin{array}{l}100,0 \% \\
\text { (1) }\end{array}$ \\
\hline & $\mathrm{C}$ & - & - & - & - \\
\hline & $\mathrm{D}$ & - & - & - & - \\
\hline \multirow[t]{4}{*}{ ALEPR } & A & $\begin{array}{c}54,2 \% \\
(33)\end{array}$ & $\begin{array}{c}22,0 \% \\
(13)\end{array}$ & $\begin{array}{c}20,3 \% \\
(12)\end{array}$ & $\begin{array}{c}96,5 \% * * * \\
(57)\end{array}$ \\
\hline & B & $\begin{array}{l}20,0 \% \\
\quad(1)\end{array}$ & $\begin{array}{l}60,0 \% \\
(3)\end{array}$ & - & $\begin{array}{l}80,0 \% \\
\text { (4) }\end{array}$ \\
\hline & $\mathrm{C}$ & $-* *$ & - & - & - \\
\hline & $\mathrm{D}$ & - & - & - & - \\
\hline \multirow[t]{4}{*}{ ALESC } & A & $\begin{array}{c}64,7 \% \\
(22)\end{array}$ & $\begin{array}{l}20,6 \% \\
(7)\end{array}$ & $\begin{array}{l}14,7 \% \\
(5)\end{array}$ & $\begin{array}{c}100,0 \% \\
(34)\end{array}$ \\
\hline & B & $\begin{array}{l}100,0 \\
(1)\end{array}$ & - & - & $\begin{array}{c}100,0 \% \\
\text { (1) }\end{array}$ \\
\hline & $\mathrm{C}$ & - & - & - & - \\
\hline & $\mathrm{D}$ & - & - & - & - \\
\hline
\end{tabular}

Fonte: Pesquisas Felisbino e Kerbauy (2009); Codato, Gouvêa e Perissinotto (2005); Venturini e Borba (2007). Obs.: *A = A democracia é sempre a melhor forma de governo; $\mathrm{B}=\mathrm{A}$ democracia às vezes é a melhor forma de governo; $\mathrm{C}=\mathrm{A}$ democracia nunca é a melhor forma de governo e $\mathrm{D}=\mathrm{E}$ indiferente ter ou não uma democracia. **Sinal para indicar \% e $\mathrm{N}$ igual a zero.***Total que não atingiu $100,0 \%$ diz respeito às opções NR/NS.

Tabela 10. Testes estatísticos São Paulo, Paraná e Santa Catarina 2007-2009, 1995-2002 e 2007.

\begin{tabular}{ccc}
\hline \multirow{2}{*}{ Elites } & \multicolumn{2}{c}{ Estatísticas } \\
\cline { 2 - 3 } & $\begin{array}{c}\text { Coeficiente de } \\
\text { contingência (CC) }\end{array}$ & $\begin{array}{c}\text { Nível de } \\
\text { significância (Sig.) }\end{array}$ \\
\hline ALESP & 0,563 & 0,031 \\
ALEPR & 0,323 & 0,059 \\
ALESC & 0,764 & 0,123 \\
\hline
\end{tabular}

Fonte: Pesquisas Felisbino e Kerbauy (2009); Codato, Gouvêa e Perissinotto (2005); Venturini e Borba (2007).

ele mostrou-se elevado $(0,764)$ e isto permite dizer que há associação significativa entre as variáveis testadas (opção ideológica do parlamentar e adesão à democracia). Já o segundo ponto a ser destacado é que não podemos afirmar uma associação para o caso paranaense, pois as estatísticas não informam isto. Talvez existam outros fatores, sejam eles endógenos ou exógenos, que possa explicar a adesão oferecida ao regime democrático.

\section{Considerações Finais}

Procuramos ao longo desta análise mostrar as percepções políticas dos parlamentares estaduais sobre a democracia no Brasil e elas permitem realizar algumas considerações sobre o tema aqui abordado.

Identificamos o reconhecimento, por parte dos membros da elite parlamentar paulista, de que estamos vivendo em uma democracia e mesmo apresentando um grau de estabilidade baixo, quando comparado com alguns países sul-americanos, esse regime está estável. Mesmo que não existam informações sobre esse tema para os deputados estaduais paranaenses e catarinenses, acreditamos que as suas opiniões acerca da estabilidade democrática sejam algo parecidas com as dos seus colegas do Estado de São Paulo, por que, 
como vimos na seção sobre a adesão à democracia, o apoio dos parlamentares paranaenses e catarinenses a esse regime é alto.

Os dados nos mostram um forte apoio dos deputados estaduais à democracia e essa adesão está muito acima do encontrado, em 2010, pelos pesquisadores associados ao Latinobarómetro $(54,0 \%$ contra $97,1 \%, 93,3 \%$ e $92,7 \%)$. São poucos os parlamentares paulistas e catarinenses que aceitam uma interrupção da democracia caso os valores que lhe são fundamentais sejam atingidos pela continuidade do regime. Não podemos dizer o mesmo para os deputados estaduais paranaenses, pois muitos deles apresentam uma disposição em aceitar o fim do regime democrático.

Vimos que a adesão à democracia apresenta um conteúdo social que obteve um bom apoio dos entrevistados. Isto significa que as políticas públicas que buscam focar no sistema universitário gratuito, na universalização da saúde, na renda mínima, nas cotas para negros, na reforma agrária em terras produtivas e improdutivas, na união civil de pessoas do mesmo sexo e na legalização da prática do aborto (essas duas últimas políticas somente se aplicam aos parlamentares paulistas) podem trazer mudanças no interior dos grupos. Na esfera política, o conteúdo da democracia pauta-se basicamente na participação do cidadão pelo voto, ou seja, a democracia tem um peso eleitoral muito grande na opinião dos entrevistados. Também é importante ressaltar que as outras formas de participação política apoiadas pelos parlamentares podem, de acordo com Jacobi (1980: 26), fortalecer os níveis de "[...] consciência e de organização da população na construção de uma real prática democrática." Noutras palavras, essas formas de participação podem alargar o escopo político da democracia.

Verificamos que as opções ideológicas dos deputados estaduais paulistas e catarinenses mostram que o apoio à democracia sofre influencia das ideologias defendidas, o mesmo não podemos dizer para os paranaenses. No entanto, acreditamos que independente da bandeira ideológica levantada pelos deputados estaduais, para eles a democracia é sempre a melhor forma de governo; mesmo que ela possa ferir alguns princípios de interesse dos parlamentares, eles vão apoiá-la como sendo o melhor regime político para se viver.

Do que foi discutido ao longo do artigo, podemos finalizar ressaltando que hoje a democracia no Brasil apresenta uma forte sustentação societal, permitindo dizer que esse regime apresenta uma robustez sociopolítica, que dificilmente deixará de existir. Dada a importância dos temas aqui discutidos, é evidente que novas pesquisas são necessárias para ampliar e confirmar os achados propiciados pelo presente texto.

\section{Referências}

Abrúcio, Fernando Luiz. 1994. Os barões da Federação. Revista Lua Nova, (33): 165-183

Abrúcio, Fernando Luiz. 1998. Os barões da Federação: os governadores e a redemocratização brasileira. São Paulo: Editora Hucitec.

Abrúcio, Fernando Luiz; Pó, Marcos Vinicius e Clemente, Roberta Aguilar dos Santos. 2008. Agências reguladoras e Assembléias Legislativas: o ultrapresidencialismo em funcionamento. Campinas, $6^{\circ}$ Encontro da ABCP.

Abrúcio, Fernando Luiz, Teixeira, Marco António Carvalho e Costa, Valeriano Mendes Ferreira. 2001. O papel institucional da Assembléia Legislativa paulista: 1995 a 1998. In F. Santos (org.), O poder Legislativo nos Estados: diversidade e convergência. Rio de Janeiro: Editora FGV.

Anastásia, Fátima. 2001. Transformando o Legislativo: a experiência da Assembléia de Minas Gerais. In F. Santos (org.), O poder Legislativo nos Estados: diversidade e convergência. Rio de Janeiro: Editora FGV.

Anastásia, Fátima, Diáz, Araceli Mateos, Inácio, Magna e Rocha, Marta Mendes da. 2009. Elites parlamentares na América Latina. São Paulo: Editora Argumentus.

Andrade, Regis Castro de. 1998. Processo de governo no município e no estado. Uma análise a partir de São Paulo. São Paulo: Editora EDUSP.

Babbie, Earl. 2003. Métodos de pesquisas de survey. Belo Horizonte: Editora UFMG.

Braga, Sérgio Soares. 2006. O que fazem os deputados estaduais paranaenses e por que? Testando o modelo do 'Segrego Ineficiente Revisto' numa escala subnacional. Belo Horizonte, $5^{\circ}$ Encontro da ABCP. Codato, Adriano Nervo, Gouvêa, Júlio César e Perissinotto, Renato Monseff. 2005. As elites administrativas, parlamentares e partidárias do Paraná, 1995-2006 (Banco de Dados), Curitiba: Núcleo de Pesquisa em Sociologia Política Brasileira, Universidade Federal do Paraná. In Consórcio de Informações Sociais, 2006. Disponível em <http:// www.nadd.prp.usp.br/cis/index.aspx>. Acesso em: 20 ago. 2010.

Corral, Margarita. 2011. El estado de la democracia en América Latina: un análisis comparado de las actitudes de las élites y los ciudadanos, In Boletin PNUD/Instituto de Iberoamérica. Universidad de Salamanca, Espanha, 2011. Disponível em: $<$ http://americo.usal.es/oir/elites/Boletines_PNUD/ Boletin_PNUD_1.pdf>. Acesso em: 10 jul. 2011. 
Couto, Cláudio Gonçalves. 1998. Negociação, decisão e governo: padrões interativos na relação ExecutivoLegislativo e o caso paulistano. In R. C. Andrade (org.), Processo de governo no município e no estado. Uma análise a partir de São Paulo. São Paulo: Editora EDUSP.

Diáz, Araceli Mateos. 2009. Los estudios sobre elites parlamentareas: el caso latinoamericano. In F. Anastasia; A. M. Diáz; M. Inácio e M. M. Rocha (orgs.), Elites parlamentares na América Latina. Belo Horizonte: Editora Argumentu.

Dicionário Eletrônico de Língua Portuguesa Houaiss (2007). Versão 2.0a.

Domingues, Mauro Petersem. 2001. Espírito Santo: produção legal e relações entre os poderes. In F. Santos (org.), O poder Legislativo nos Estados: diversidade e convergência. Rio de Janeiro: Editora FGV.

Felisbino, Riberti de Almeida. 2007. Origem social, perfil de carreira e patrimônio: um estudo da elite parlamentar da Câmara dos Deputados nos governos de Fernando Henrique Cardoso (1995-2002). Tese (Doutorado em Ciências Sociais), Universidade Federal de São Carlos.

Felisbino, Riberti de Almeida. 2008. Instituições e valores políticos: as opiniões das elites parlamentares dos países do Mercosul em perspectiva comparada. Campinas, $6^{\circ}$ Encontro da ABCP.

Felisbino, Riberti de Almeida e Kerbauy, Maria Teresa Miceli. 2009. Democracias comparadas dos Estados brasileiros: opiniões e valores das elites parlamentares das Assembléias Legislativas de São Paulo e Maranhão (Banco de Dados), Araraquara: Faculdade de Ciências e Letras, Universidade Estadual Paulista.

Figueiredo, Argelina Cheibub e Limongi, Fernando. 1999. Executivo e Legislativo na nova ordem constitucional. São Paulo: Editora FGV.

Grohmann, Luis Gustavo Mello. 2001. O processo legislativo no Rio Grande do Sul: 1995 a 1998. In F. Santos (org.), O poder Legislativo nos Estados: diversidade e convergência. Rio de Janeiro: Editora FGV.

Holanda, Felipe Macedo. 1990. O processo de tomada de decisões na Assembléia Legislativa de São Paulo. Estudo de Caso. São Paulo: Centro de Estudos de Cultura Contemporânea.

Jacobi, Pedro Roberto. 1980. Movimentos urbanos no Brasil. Revista Brasileira de Informação Bibliográfica em Ciências Sociais, Rio de Janeiro, (9): 22-30.

Latinobarómetro. Disponível em: <http://www. latinobarometro.org/>.

Lima, Maria Regina Soares e Cheibub, Zairo Borges. 1996. Instituições e valores: as dimensões da democracia na visão da elite brasileira. Revista Brasileira de Ciências Sociais, São Paulo, (31): 83-110.
Machado, Fábio Ribeiro. 2008. Comissões, produção legislativa e o papel da informação: um estudo comparativo em Assembléias estaduais. Campinas: $6^{\circ}$ Encontro da ABCP.

Moisés, José Álvaro. 2005. A desconfiança nas instituições democráticas. Revista Opinião Pública, Campinas, XI(1): 33-63.

Moisés, José Álvaro. 2010. A confiança e os seus efeitos sobre as instituições democráticas. In Moisés, José Álvaro (org.). Democracia e confiança: por que os cidadãos desconfiam das instituições públicas? São Paulo: Editora EDUSP.

Montenegro, Nelson. 2010. A barganha de subdesenvolvimento. Recife, $7^{\circ}$ Encontro da ABCP.

Moraes, Filomeno. 2001. A dinâmica legislativa na Assembléia do Estado do Ceará: 1995 a 1998. In F. Santos (org.), O poder Legislativo nos Estados: diversidade e convergência. Rio de Janeiro: Editora FGV.

Pait, Heloisa. 1990. Isenção de ICMS para rádio e TV. Centro de Estudos de Cultura Contemporânea, São Paulo.

Pereira, André Ricardo. 2001. Sob a ótica da delegação: governadores e Assembléias no Brasil pós-1989. In F. Santos (org.), O poder Legislativo nos Estados: diversidade e convergência. Rio de Janeiro: Editora FGV.

Perissinotto, Renato Monseff e Braunert, Mariana Bettega. 2006. A direita, a esquerda e a democracia: os valores políticos dos parlamentares paranaenses (1995-2002). Revista Opinião Pública, Campinas, 12(1): 114-135.

Perissinotto, Renato Monseff, Codato, Adriano Nervo, Fuks, Mário, Braga, Sérgio Soares (orgs.). 2007. Quem governa? Um estudo das elites políticas do Paraná. Curitiba: Editora da UFPR.

Reis, Elisa Pereira. 2000. Percepções da elite sobre pobreza e desigualdade. Revista Brasileira de Ciências Sociais. São Paulo, 15(42): 143-152.

Rocha, Marta Mendes e Costa, Alessandra. 2010. Centralização decisória e comissões parlamentares nos Legislativos estaduais brasileiros. Recife, $7^{\circ}$ Encontro da ABCP.

Rodrigues, Leôncio Martins. 1987. Quem é quem na constituinte: uma análise sócio-política dos partidos e deputados. São Paulo: OESP-MALTESE.

Sáes, Manuel Alcántara. 2004 ¿Instituciones o máquinas ideológicas? Origen, programa y organización de los partidos latinoamericanos. Barcelona: Institut de Ciències Politiques i Socials.

Sáes, Manuel Alcántara. 2008. La escala de la izquierda: la ubicación ideológica de presidentes y partidos de izquierda en América Latina. Revista Nueva Sociedad, (217): 72-85. Disponível em: <http://www.nuso.org/ upload/articulos/3548_1.pdf>. Acesso em: 29 maio 2011. 
Souza, Márcia Teixeira. 2008. Avaliação dos mecanismos institucionais da Comissão de Fiscalização de Controle da Assembléia Legislativa de São Paulo. Campinas, $6^{\circ}$ Encontro da ABCP.

Tomio, Fabrício Ricardo de L. e Ricci, Paolo. 2008. Conexão eleitoral, processo legislativo e estratégias parlamentares nas Assembléias Legislativas estaduais. Campinas, $6^{\circ}$ Encontro da ABCP.

Tomio, Fabrício Ricardo de L. e Ricci, Paolo. 2010. Instituições e decisões: estudo comparativo do processo legislativo nas Assembleias Estaduais. Recife, $7^{\circ}$ Encontro da ABCP.
Venturini, Marco Aurélio e Borba, Julian. 2007. Elites políticas e a democracia: os valores políticos dos parlamentares catarinenses da $16^{\circ}$ Legislatura, 2007 (Banco de dados). Florianópolis: Universidade Federal de Santa Catarina. In Consórcio de Informações Sociais, 2009. Disponível em: <http://www.nadd. prp.usp.br/cis/index.aspx>. Acesso em: 12 jan. 2011. Zucco Júnior, César. 2009. Esquerda, direita e governo: a ideologia dos partidos políticos brasileiros. Oxford, Seminário "Legislator views of brazilian Governance". Disponível em: <http://www.princeton. edu/ zucco/papers/paper-esquerdadireitagoverno. br.pdf $>$. Acesso em: 07 jun. 2011. 